\title{
Discussion on the Bilingual Teaching Staff Construction of College Language Training Course (IELTS)
}

\author{
Lei Wang \\ Jilin Business and Technology College \\ Changchun City, Jilin, 130000 \\ 182076127@qq.com
}

\begin{abstract}
Teaching of college IELTS training course is unique, which serves for candidates attending International English Language Testing System (IELTS), and students attending the training focus on mastering basic English communication skills. Bilingual teaching mode can effectively promote the language communication between teachers and students, and improve students' oral communication skills, which are consistent with the requirements of IELTS training courses. Currently, the overall quality of bilingual teaching staff of language training course (IELTS) in Chinese colleges is not satisfactory, and there are also many problems, seriously restricting the bilingual teaching effect of IELTS.
\end{abstract}

Keywords—college IELTS; training course; bilingual teaching; mode; teaching staff

\section{INTRODUCTION}

In recent years, with the deepening understanding of quality education in China, and the introduction and implementation of various reform measures of education system, many universities begin to imitate the advanced education systems of Western countries. [1] The obvious manifestations are a variety of foreign language teaching materials entering into the curriculum system of colleges, and bilingual teaching mode becoming the new trend, especially the teaching of language training courses focusing on improving students' proficiency in English, such as IELTS and TOEFL. Bilingual teaching mode in China is still at the exploratory stage, a variety of related systems are still in perfecting stage, and many problems appear in the colleges' practicing process of this mode, which seriously restrict the improvement of teaching effectiveness. This paper mainly discusses the bilingual teaching staff construction of college language training course (IELTS), hoping to provide important reference for relevant research.

\section{InTERNATIONAL ENGLiSH LANGUAGE TESTING SySTEM (IELTS)}

IELTS is divided into two categories, one is academic class, and the other is training class. And the focuses of these two classes are distinct. IELTS of academic class focuses on assessing students' comprehensive English level, to evaluate whether the student can meet the relevant requirements of undergraduate or master's degree in foreign universities, and its

“Effective Improving Theory and Method of College Students' Academic IELTS Score under the Mode of Sino-foreign Cooperative Education”, Project No.: No. 390, Educational, Scientific, and Cultural Organization of Jilin Province [2015] applicable objects are students preparing to study abroad; IELTS of training class focuses on testing candidates' English skills, and its applicable objects are people planning to emigrate abroad, work abroad or apply for overseas training courses instead of applying for foreign degrees. The examination structure of IELTS of training class is divided into four parts, namely, listening, speaking, reading and writing. Reading comprehension of IELTS of Training class has three sections and forty questions with different difficulty levels. There are 14 reading questions in the first section, and 13 questions in both second section and third section. The first part generally consists of two to three essays, the content involves various subjects, some are from advertisements, and some from promotional materials, while most are related with life; the second section generally has two short articles, and the contents are mostly university course descriptions, student recruitment brochures, regulations, library guidelines, and other similar sources; the third part is relatively difficult, which are generally selected from authoritative magazines, newspapers, novels and so on. Writing part generally requires the writing of two articles, the first article generally is to write a personal letter according to the given problem or related events, the form of the letter can be formal, informal or semi-formal, and the article usually requires about 150 words, but preferably no more than 150 words; the second article usually proposes a viewpoint to a problem or different argument or a specific topic, candidates can provide a solution to the problem, or demonstrate and evaluate the views, or express their views based on the information provided in the subject, the general form of writing is in the way of writing paper, and the words generally cannot be less than 250 words, but cannot exceed too much. The speaking section of IELTS is to test candidates' oral English level through the one-to-one communication between candidates and examiners. The speaking section is divided into three parts, and candidates can use different oral expression skills accordingly.

IELTS scoring rules: the content of the examination is divided into listening, speaking, reading and writing parts, the scoring of each part is individual, the total score is 9 points, the lowest score of 0 , the resulting total score is the average number of the total scores of the four parts, and the nearest integer or half the score is applied. IELTS scores can roughly reflect students' English level. 
TABLE I.

\begin{tabular}{|l|l|}
\hline $\mathbf{9}$ points & Be able to use English appropriately, accurately and fluently, and fully understand the language. \\
\hline $\mathbf{8}$ points & $\begin{array}{l}\text { Use English proficiently, and have only a few errors. May have misunderstandings in an unfamiliar context, and } \\
\text { can master the complex detail of argumentation well. }\end{array}$ \\
\hline $\mathbf{7}$ points & $\begin{array}{l}\text { Can communicate effectively in English, and occasionally have inaccurate, inappropriate or wrong understanding. } \\
\text { Can master complex English, and understand detailed reasoning. }\end{array}$ \\
\hline $\mathbf{6}$ points & $\begin{array}{l}\text { Can use English effectively, and despite inaccurate, inappropriate or wrong understanding, can understand complex } \\
\text { English in a familiar context. }\end{array}$ \\
\hline $\mathbf{5}$ points & $\begin{array}{l}\text { Can use some of English, and understand the general meaning in most cases. Despite the frequent mistakes, can } \\
\text { conduct basic communication in familiar areas. }\end{array}$ \\
\hline $\mathbf{4}$ points & $\begin{array}{l}\text { Have basic understanding only in a familiar context, have frequent problems in understanding and expression, and } \\
\text { cannot use complex English. }\end{array}$ \\
\hline $\mathbf{3}$ points & Can conduct simple communication in a very familiar context, and have frequent communication barriers. \\
\hline $\mathbf{2}$ points & Cannot conduct effective communication in non-familiar context. Cannot understand or read English. \\
\hline $\mathbf{1}$ point & Cannot communicate in English. \\
\hline $\mathbf{0}$ point & In the lack of rating basis \\
\hline
\end{tabular}

\section{REQUIREMENTS OF COLLEGE IELTS TRAINING} COURSES FOR TEACHER QUALITY

Teaching has always been one complex activity, and IELTS can be said as a newly emerging thing in China, which is different from various English tests under the exam-oriented education mode in China. IELTS proposes higher requirements for students' English proficiency, and the difficulty of the test also raises higher requirements for the quality of university teachers. [2]

\section{A. Strong Professional Foundation of English}

As college English teachers, professional knowledge of English is the most basic requirement of professional quality. Specifically, teachers must be able to master the knowledge hierarchy of college English College discipline, their knowledge level must reach the level of IELTS, they must know knowledge related to language theory of college English, such as vocabulary, grammar rules, phonetic rules, writing style, English phonetics, semantics, lexicology, stylistics, linguistics, etc., they must be very familiar with the cultural background of English speaking countries, and they also must have very good English listening, speaking, reading, writing and translating capabilities. In addition, IELTS exam will change along with the changes of social conditions, so teachers must continue to expand their knowledge of English and deepen the mastery of English skills, so as to keep pace with the changing requirements of the IELTS exam.

\section{B. Broad Horizon}

IELTS is currently one of the most difficult international standardized tests of English, as is recognized by the entire world, and the knowledge involved in the test are wide, covering various aspects like politics, economy, culture, society, life, science and technology, military and so on. As the popular saying goes, if you want to teach others a little knowledge, you must have mountains of knowledge, and despite the exaggeration, the saying has its own reason. As IELTS training teachers, in addition to have a solid professional knowledge, broad horizon and extensive knowledge are also very important, because only when teachers have broad horizon, they can keep up with the standards of international exam, can guide the candidates to conduct learning in the right way, and can train students' English ability in accordance with international standards. [3] Especially for candidates receiving long-term oriented education, teachers need to transform students' learning thinking with their broad horizons, and actively explore teaching mode suitable for cultivating students' English comprehensive ability, to match the difficulty of the IELTS test.

\section{Mastering a Certain Amount of Educational Psychology Knowledge}

The aim of mastering a certain amount of educational psychology knowledge is to implement individualized teaching strategies based on the learning law and psychological law of college students. Teaching of IELTS preparation is a newly emerging thing in the field of language education in recent years, students' learning law, adaptation capacity, teaching law and teaching strategies are all still in the exploratory stage, and theoretical research on these areas is relatively insufficient. Therefore, teachers need to explore the teaching methods fit for students' cognitive rule to IELTS under the guidance of educational psychology, to improve teaching efficiency. IELTS teachers should take the initiative to grasp educational psychology related knowledge, and actively study the teaching content and teaching strategies of IELTS, explore teaching law, and improve teaching efficiency under guidance of the ideology. [4]

\section{Abundant English Teaching Experience}

Teaching of IELTS preparation focuses on actual effect and effectiveness and emphasizes skills training. Students attending IELTS training courses are uneven and generally have their own personalities, and to improve the students' English proficiency within a short time undoubtedly has certain requirements for the teacher's teaching experience and teaching proficiency. [5] On the basis of existing teaching experience, teachers must be able to grasp the characteristics of IELTS course content quickly, accurately determine the language acquisition mode suitable for teaching object, and implement targeted teaching strategies based on the student's personality and learning rules. And teachers without teaching experience cannot master these teaching skills in a short period of time. 


\section{E. Good Teacher's Ethics}

Teacher's duty is 'imparting knowledge and educating people”, and the learning and teaching of language is a boring, tedious activity, requiring very strong perseverance of both teachers and students. What's more, as IELTS course is more difficult than general university courses, and IELTS test is also more difficult than general English exam, if the teachers have no good ethics, it is difficult for them to adhere to provide students with high-quality education and to adapt to the changing requirements of IELTS. Only when the teachers have good ethics, they are able to continuously innovative teaching methods from the perspective of actual effect and effectiveness, to strengthen the training of students, to enable students to practically master the English related knowledge and skills, and to achieve the teaching goal, which is also the best guarantee for the efficiency of student learning. [6] In addition, the English level and cultural quality of IELTS candidates are generally higher, and teachers with good ethics are more likely to elevate students' learning emotion and help them build confidence for the test.

\section{Status Analysis of the Bilingual TEACHING STAFF CONSTRUCTION OF COLLEGE LANGUAGE TRAining COURSE} (IELTS)

Since IELTS course is for foreign language exam, bilingual education is more conducive to cultivating students' ability to use English. Currently, the bilingual teaching staff situation of college IELTS course in China is not ideal, and has following characteristics.

\section{A. Qualified teachers are lacking, and the overall quality is not high.}

High-quality teacher with bilingual capability and high English professional quality is an important prerequisite of conducting bilingual education in Colleges IELTS course, and also one of the key factors of conducting bilingual education in IELTS training course. Teaching activity is a unified process between "teaching" and "learning", English teaching lays more emphasis on the high integration between "teaching" and "learning" and the interaction between students and teachers, and the level of teachers' quality directly determines the effect of interaction. For conducting bilingual education in IELTS training course to guarantee the teaching results, teacher's English level, especially oral communication skill, is an important guarantee. However, in Chinese universities, although a lot of English teachers have some English knowledge, due to the influence of exam-oriented education, their overall quality cannot meet the requirements of IELTS training course, especially in the aspect of pronunciation skills, and cannot reach IELTS standards. [6] Some universities employ teachers who have studied abroad, but it is still difficult for some teachers to teach entirely in English. Only a portion of foreign teachers can keep up with the English level of IELTS, but their teaching methods are difficult to adapt to the thinking of domestic students, so that it is difficult to ensure the teaching results. In conclusion, the bilingual teaching staffs of IELTS training course in China are in shortage, and the overall quality of coaching teachers is not ideal.

\section{B. Knowledge structure is single, and international perspective is lacking.}

Affected by China's traditional education ideas and patterns, the knowledge structure of many teachers teaching IELTS in universities is unreasonable and mostly single, and many teachers only focus on knowledge related to English language subject, and lack basic understanding on the history, culture, politics, economy and education system of English-speaking countries, so in the process of teaching, many teachers cannot explain about the IELTS course content by combining the history and culture of western countries. Furthermore, some teachers rarely learn overlapping disciplines of English and language-related theoretical knowledge, such as linguistics, English grammar rules, English semantics, etc., which will limit the teaching levels of IELTS bilingual teachers and the ability of guiding students to quickly master the English knowledge to some extent. In addition, many bilingual teachers lack basic understanding of the developments in international frontier, such as the difficulty standard of international tests, international scoring standard for English tests and thinking of setting a question, so that they cannot guide students to correctly master the regulations of IELTS exam, thus limiting the students' achievements in the test to some extent.

\section{The structure of teachers is not professional or reasonable enough.}

Currently, teachers engaging in bilingual teaching of IELTS in colleges are basically foreign teachers and scholars, and a small number of them are professors having overseas studying experience or teaching experience, while local teachers of foreign languages are very few. Such teaching body barely receives any formal training in bilingual education, and they essentially lack basic theoretical knowledge of bilingual teaching, and basically rely on their own exploration and experience summary to decide the strategies and methods applied in bilingual teaching and the final standards. Therefore, they are in lack of the guidance of scientific teaching theory in teaching. In addition, due to the special nature of the structure of teachers, their abilities and job titles are difficult to obtain timely optimization, so that important guarantee cannot be provided for the teaching effectiveness of IELTS course.

\section{There are no professional quality certification and training system of bilingual teachers.}

Professional quality certification and training system of bilingual teachers are lacking, which is an important factor limiting the overall quality improvement of bilingual teachers of college IELTS training course in China. At present, although China has introduced a number of bilingual certification and training systems abroad and also has modified and improved these systems based on China's actual conditions, it is still in lack of the corresponding systems, management mechanisms and facilities supporting training of these systems, which also limits the development of IELTS bilingual training teachers to some extent. 


\section{COUNTERMEASURES}

It can be observed from the above analysis that the quality of IELTS bilingual training teachers needs to be further strengthened, and I think that the following countermeasures can be applied.

\section{A. Conduct Training on IELTS Bilingual Training Teachers}

The overall quality of teachers is the fundamental guarantee of the bilingual teaching effect of IELTS training course. First, according to the requirements of IELTS, namely, the requirements of listening, speaking, reading, writing and translating, strengthen the teachers' capacity in these aspects. Training in English reading and speaking can be combined as one, colleges should provide specialized training for the teachers for at least three semesters, to continuously improve teachers' reading ability, correct their pronunciation, intonation and language speed, and improve the consistency and accuracy of their language expression, thus ensuring the reading and speaking teaching ability of the teachers; reading training can be conducted by asking trainees to read a lot of English materials; then, vocabulary is an important guarantee for reading effect, the English vocabulary of students passing CET-6 must have 5000 to 6000 words, and the vocabulary of IELTS test is far more than that of CET-6, so the teachers in training must be able to master a large number of vocabulary, at least exceeding the vocabulary of CET-6. Finally, training of grammar and knowledge background, English learners may share the feeling that even if they know every word in the sentence, they still not necessarily understand the meaning of the whole sentence, and the main reason is the lack of relevant grammar knowledge and cultural background. For example, "Love me, love my dog", people who do not understand Western culture will directly translate this sentence as “喜歡 我就喜歡我的狗”, but the correct translation of this sentence should be “愛屋及烏”. Because in Western countries, the dog has a very high status, and even can be equal with human, which is different from Chinese culture.

\section{B. Introducing Professional Bilingual Teachers in Various Ways}

Introducing high-quality professional bilingual teachers is a fast way to adjust the structure of bilingual teachers of IELTS training courses. The introduction of high-quality professional bilingual teachers should not be limited to foreign teachers or scholars studying abroad, universities should find teachers in various ways, and especially the teachers having a higher level of English as well as many years of teaching experience should be the focus of the introduction. But it should be noted that the recruitment standard must be strict and the evaluation of bilingual teaching ability must be emphasized in the introduction. As the teaching of IELTS course demands higher bilingual teaching ability for the teachers than the teaching of general subjects, the introduction of specialized teachers best applies the rule of one-vote veto.

\section{Carrying out International Cooperation, and Creating High-level IELTS Bilingual Teaching Staff}

IELTS is a test of international standards, so that teachers must have international teaching perspective. Carrying out international cooperation plays a positive and promoting role in broadening the international perspective of the teachers, correcting English pronunciation and understanding the historical and cultural background of English-speaking countries. There are many ways of carrying out international cooperation, for example, exchanging teachers to receive bilingual teaching training, that is, sending good English teachers of the universities to foreign universities for training, while accepting teachers of foreign universities to receive Chinese training, or exchanging teachers from both sides to engage in language teaching in the language faculties, etc.

\section{CONCLUSIONS}

This paper summarizes the requirements of college IELTS training course for teachers' quality, analyzes the status of bilingual teaching staff construction of colleges IELTS course, and then discusses the countermeasures of constructing highquality bilingual teaching staff on this basis, hoping to provide important reference for relevant research.

\section{REFERENCES}

[1] Zhang Lijuan. Study on the Bilingual Teaching Staff Construction in Chinese Universities[J]. Journal of Peking University (Philosophy and Social Sciences Edition), 2007 (5): 265-267. (In Chinese)

[2] Tricia Hedge. Teaching and Learning in Language Teaching[M]. Shanghai: Shanghai Foreign Language Education Press, 2003 (11): 1517. (In Chinese)

[3] Zuo Huanqi. Emphasis on Social Linguistics and Psycholinguistics Problems Involved in Bilingual Teaching[J]. Global Education, 2003 (2) 12-14. (In Chinese)

[4] Hu Chunhua. Backwash Effect in IELTS and English Teaching[J]. Journal of Guangxi College of Education, 2009 (2). (In Chinese)

[5] Gu Jiabei. IELTS Writing Routine Analysis and Examples[M]. Qunyan Press, 2008: 144-161. (In Chinese)

[6] Liu Hongbo. The Most Simplified IELTS Writing[M]. Beijing Language and Culture University Press, 2010: 48-58. (In Chinese) 